\title{
TRACKING ENVIRONMENTAL ISSUES AND ACTIONS
}

\author{
Jaswant Sokhi $^{1}$ and Kumari Anjali ${ }^{2}$ \\ ${ }^{1}$ Sikkim Professional University, 8th Mile, Budang, West Sikkim \\ ${ }^{2}$ Indira Gandhi National Open University, School of Sciences, Maidan Garhi, New Delhi
}

\section{Review Article}

Received: 08.04.2021

Accepted: 15.04.2021

Published: 22.04.2021

\begin{abstract}
Life support system or environment of Earth is undergoing rapid \&unprecedented changes in recent decades. How to follow up and understand emerging environmental issues and concerns from local to global level employing new and emerging tools and technologies is presented in this communication. An experiential perspective for the benefit of students, professionals, researchers and citizens is presented here in to further the debates regarding actions and programmes to be taken up.
\end{abstract}

Keywords: Anthropocene, global warming, climate change, biodiversity, ground water depletion, pollution, GM organisms, crops, fruits and vegetables, depletion of ozone layer, ozone build up near surface of Earth, wastes, E-wastes, pollution in outer space, interlinking of rivers, sustainable agriculture, forestry, energy, plastics, human-animal conflicts, nuclear weapons, bioweapons, alien species /invasive species, rivers: Ganga, Yamuna, disconnect with nature, value of ecological services, industrial \& nuclear accidents, population pressure, pandemics and syndemics, space debris orbiting Earth, and declining number of pollinators, largely bees.

\section{INTRODUCTION}

Environment and contemporary issues are concerns of people of all walks of life. How to keep oneself aware about the happenings and actions towards environment protection and addressing environmental issues at local, regional and global levels is to be learnt and devised by people as per their experiences, interests and resources. An experiential account using mass communication media like television, radio, newspapers, journals, magazines, internet, mobile phone, laptop or desktop is being presented in this paper.

\section{Contemporary Environmental Issues}

In the present age, Anthropocene, much-discussed environmental concerns, issues and developments are as follows:
Global warming, climate change- Global warming is rise in average global temperature because of increasing concentration of greenhouse gases in the atmosphere. Long term changes in climate parameters such as precipitation, temperature and wind patterns have direct bearing on global warming and climate change.

Biodiversity - the variety and variability at species, genetic and ecosystem levels of all forms of life on Earth constitutes biodiversity.

Ground water depletion- refers to drop in groundwater levels due to sustained withdrawal by pumps and other means for various uses. This situation occurs when withdrawals exceed the replenishment of underground aquifers.

*Corresponding author: spujsokhi@gmail.com 
Pollution - denotes contaminants in natural environment that result in harmful changes in the life support system - air, soil, water (freshwater and marine water). Pollution is due to various chemical substances and forms such as mercury and heavy metals, energy, noise, thermal, light, municipal and industrial wastes, plastics, radioactive or nuclear remains and different kinds of data in present times of digital age.

GM organisms, crops, foods- A genetically modified organism (GMO) is one whose genetic material has been altered using genetic engineering techniques to produce better quality products and fulfil the needs of mankind all over the world.

Depletion of ozone layer - Gradual thinning of Earth's ozone layer in the upper atmosphere, caused by chemical compounds - gaseous chlorine or bromine released from industry and other human activities. Thinning of ozone layer is most marked in the polar regions, especially over Antarctica. Ozone depletion is of concern because it leads to increased amount of ultraviolet (UV) radiation that reaches Earth's surface, due to which health problems likes kin cancer, cataracts, genetic and immune system damages reportedly occur.

Ozone build up near surface of Earth - Since 1900, ozone concentration near the Earth's surface has been increasing mainly due to vehicular exhausts and emissions from factories, power plants, and refineries. This is an issue of immense concern in present times.

Wastes (solid, semisolid, liquid, gaseous, municipal, industrial, construction, biomedical, commercial, mining, radioactive and agricultural) refers to garbage, detritus, sludge, and other discarded materials.

E-wastesare electrical and electronic equipment, whole or in part discarded as waste by the consumer or bulk consumer as well as rejects from manufacturing, refurbishment and repair processes.[Published in The Gazette of India, Extraordinary Part-II, Section 3, SubSection (I)].

Government of India, Ministry of Forest and Climate Change $23^{\text {rd }}$ March,2016.

Pollution in outer space of Earth -The increasing number of debris, junk, wastes, trash, garbage, chemicals due to defunct manmade objects in space, or in Earth's orbit, because of accidents of space crafts or their destruction as the spacecrafts have become defunct-all these have polluted the outer space and are also posing grave threat to the weather forecasting, communication, and military satellites.

Interlinking of rivers - it is a civil engineering mega project in our country that envisages to interlink various rivers in the country by forming a series of reservoirs and canals with an aim that water is equitably available to all and to mitigate the problems of drought and flooding in several parts of the country.

Sustainable agriculture, forestry- is farming in sustainable ways, whereby society's present food, feed and textile needs, without compromising ability of current or future generations to meet their needs. Whereas sustainable forestry is the management of forests according to the principles of sustainable development. It has to keep a balance between ecological, economic and socio-cultural paradigms.

Energy(renewable, alternative energy sources) Energy moves the wheel of life. All kinds of processes require energy. Energy can be obtained from various sources which can be divided into non-renewable and renewable resources. Fossil fuels - oil, natural gas and coal are non-renewableresources of limited availability. Alternate sources of energy - renewable resources, such solar energy, wind energy, hydropower, energy from biomass, geothermal energy have been widely tapped in recent times.

Plastics -The term plastic is derived from Greek word 'plastikos' meaning fit for molding. These are synthetic materials made from organic polymers like polyethylene, PVC, and nylon. Being easily moldable they are used to make various objects such as toys, medical devices, automobiles, packaging materials, buildings and various fixtures in them, bottles, household articles and several products used in modern life.

Human wildlife conflicts -Are abbreviated as HWC. It refers to varied interactions between people and wild animals, with consequences for people, their resources, wildlife and their habitats (IUCN 2020). HWC are caused by competition for shared natural resources between people and wildlife. These influence food security and the well-being of both people and animals. In many regions these conflicts have intensified over recent decades as a result of human population growth and the transformation of land use. HWC are serious global threats, hampering 
sustainable development, food security and conservation in urban and rural landscapes.

Nuclear weapons -Nuclear weapons (= atom bomb, nuke, atomic bomb, nuclear warhead, A-bomb, or nuclear bomb) are explosive devices that derive their destructive force from nuclear reactions - either fission (fission bomb) or from a combination of fission and fusion reactions (thermonuclear bomb). Both types of bombs release huge amounts of energy from relatively small amounts of matter.

Bioweapons - Also known as BiologicalWeapons, Biological Warfare, Bioterrorism attacks and Germ Warfareare biological organisms, and substances (toxins or infectious agents such as bacteria, viruses, insects, fungi and replicating entities) derived directly from living organisms, that can be used to cause death or injury to humans, animals, or plants.

Biological agents, like anthrax, botulinum toxin and plague can pose a difficult public health challenge causing large numbers of deaths in a short amount of time while being difficult to contain. Bioterrorism attacks also result in epidemics, for example, Ebola or Lassa viruses have been used as biological agents.

Bioweapons constitute a subset of a larger class of weapons referred to as weapons of mass destruction, which also includes chemical, nuclear and radiological weapons. The use of biological agents is a serious problem, and the risk of using these agents in a bioterrorist attack is increasing in recent years.

Alien species /invasive species -Invasive alien species are ones that are/get introduced, accidentally or intentionally, outside their natural habitats and in long run they invariably threaten biological diversity. Alien species /invasive species are from all taxonomic groups, including animals, plants, fungi and microorganisms. Many of them lead to extinction of native species and eventual ecological disturbance. These impacts have marked socio-economic value. Invasive species adversely affect the invaded habitats and bioregions, causing ecological, environmental, and/or economic damage. On the other hand, many a times, their spread has beneficial effects too.

Rivers: Ganga, Yamuna -Yamuna is the second-largest tributary river of the Ganga and the longest tributary in India. It travels a total length of 1,376 kilometres. Ganga, a trans-boundary river of Asia, flows through India and Bangladesh. It flows to a length of 2,525 kms and empties into the Bay of Bengal. These rivers are lifelines of the places through which these passes. On the other hand, they are also conduits of various by products of societies.

Disconnect with nature, value of ecological services With growing urbanization, and globalization, humans are increasingly being disconnected with nature. People are realizing and are reconnecting with nature. Ecological services such as supporting (nutrient cycling, soil formation), provisioning (food, fresh water, medicines, oils, fats, essential oils, gums \& resins, wood, fibre, fuel), regulating(climate, flood, drought, disease, water purification), cultural (aesthetic, spiritual, educational, recreational), security (personal safety, ensured resources access, security from disasters), basics for a fulfilling life (adequate livelihood, nutrition, shelter), health (strength, vitality, wellness, pure air, water and food), social relations (cohesion, respect, helping attitude), freedom (individual's values, being self).

Industrial \& nuclear accidents -Three Mile Island accident (1979), SL-1 accident (1961), The Bhopal disaster (night of 2-3 December 1984), Chernobyl disaster (1986), and Fukushima Daiichi nuclear disaster (2011) are notable industrial and nuclear accidents.Such accidents involved loss of precious life and large monetary costs for remediation of the affected sites.

Population pressure - The world population is growing by more than 90 million per year, of which $93 \%$ is in developing countries. This could hamper their economic development. Population increase in past decades has been a gradual phenomenon and Earth's natural resources were being replenished by nature for this increase. Recent studies indicate that besides population increase natural resources are being consumed in greater amounts than their rate of replenishment. The increase in human population has become a major cause of environmental concern of late.

Pandemics and Syndemics -Pandemic is global epidemic or infectious disease that spreads to more than one continent. Syndemic, a synergistic epidemic, is aggregation of two or more concurrent or sequential epidemics or disease clusters in a population with biological interactions, which lead to burden of disease. This term was developed by Merrill Singer in mid 1990s. 
Space debris orbiting Earth- Millions of pieces of debris (defunct satellites, pieces of rockets and spacecrafts, equipments, chemicals and tools that astronauts accidently dropped in space) are swirling around at high speeds in space near Earth. These are matters of concern as they have caused accidental collisions in space damaging communications, weather and other satellites and rockets causing environmental and economic damage. There are objects greater than $10 \mathrm{~cm} 34,000$ in number; objects 1 $10 \mathrm{~cm}$ in size 900,000 in number; and objects $1 \mathrm{~mm}$ to $1 \mathrm{~cm}$ in size 128 million in number (Source: European Space Agency, 8 January 2021), (LiveMint, 16.01.2021).
Declining number of pollinators, largely bees because of loss of habitat, use of agrochemicals, pesticides and climate change has bearing on production of crops, fruits and vegetables.

The list as above may not be complete as of now. It could be expanded and updated every now and then.

One needs to be aware that following actions are being taken and realised for the safeguard of both living beings and Earth's environment.

\begin{tabular}{|c|c|}
\hline S. No. & Actions taken \\
\hline 1. & Local, national, regional, global \\
\hline 2. & $\begin{array}{l}\text { Institutions \& organizations - UN (United Nations), UNEP (United Nations Environment } \\
\text { Programme), IPCC (Intergovernmental Panel on Climate Change) }\end{array}$ \\
\hline 3. & Bills, legislations, policies, Protocols \\
\hline 4. & $\begin{array}{l}\text { Governance/ monitoring - Ministry, NGT (National Green Tribunal), EPCA [Environmental } \\
\text { Pollution (Prevention and Control)] Authority, CPCB (Central Pollution Control Board) }\end{array}$ \\
\hline 5. & NGO (Non-governmental organization) \\
\hline 6. & $\begin{array}{l}\text { Environment days - House sparrow, forestry, water, meteorological, migratory birds, ozone, oceans } \\
\text { \& no tobacco day. }\end{array}$ \\
\hline 7. & Environment years -April 2019 to March 2020 Construction Technology Year \\
\hline 8. & Green buildings \\
\hline 9. & $\begin{array}{l}\text { Forests Rights Act - Forest Act (Schedule Tribes and other traditional forest dwellers (recognition of } \\
\text { forest rights Bill, 2006) }\end{array}$ \\
\hline 10. & Civil nuclear liability bill \\
\hline 11. & Rejuvenation \& restoration of defunct water bodies \\
\hline 12. & Environment education \\
\hline 13. & E-waste (management) Amendment Rules, 2018 \\
\hline 14. & National Mineral Policy \\
\hline 15. & Mass awareness campaigns \\
\hline 16. & Green budgets \\
\hline 17. & Non-conventional \& renewable energy resources \\
\hline 18. & Green political agendas \\
\hline 19. & Smart cities \\
\hline
\end{tabular}


To be an informed citizen and how to track environmental issues, and be an environmental protection soldier, the following resources can easily be tapped:

\section{How to track? - modes of mass communication}

\section{$>$ News papers}

The above-mentioned resources have following attributes:

\begin{tabular}{|l|l|}
\hline S.No. & Nuances \\
\hline 1. & Latest issues, decisions developments \\
\hline 2. & Written medium \\
\hline 3. & Powerful medium \\
\hline 4. & Responsible \\
\hline 5. & Specific thrust \\
\hline 6. & Powerful media for molding opinions \\
\hline 7. & Affordable \\
\hline 8. & Fast evolution taking place, paper to digital sources are increasing day by day \\
\hline 9. & Daily tracking is essential \\
\hline 10. & Record keeping is a must \\
\hline 11. & Information and facts are retrievable \\
\hline 12. & Interpretations need to be holistic and sound \\
\hline 13. & Different perspectives need to be considered \\
\hline 14. & Tracking with newspaper - with www / original source is of immense help \\
\hline 15. & Article can be retrieved with the help of google any time \\
\hline 16. & Editorials add mature, objective analyses to ones insight \\
\hline 17. & + \&-aspects of one and all may be taken into account too \\
\hline
\end{tabular}

Following figures exemplify latest updates about environment.
World Wide Web
$>$ Mobile phone
$>$ Laptop/desktop
$>$ Internet 
One gets to know of the current announcements and schemes by the Ministry of Environment, Forest and climate change.
The following screen shot displays how making quality water available in market turns out to be a profitable enterprise.

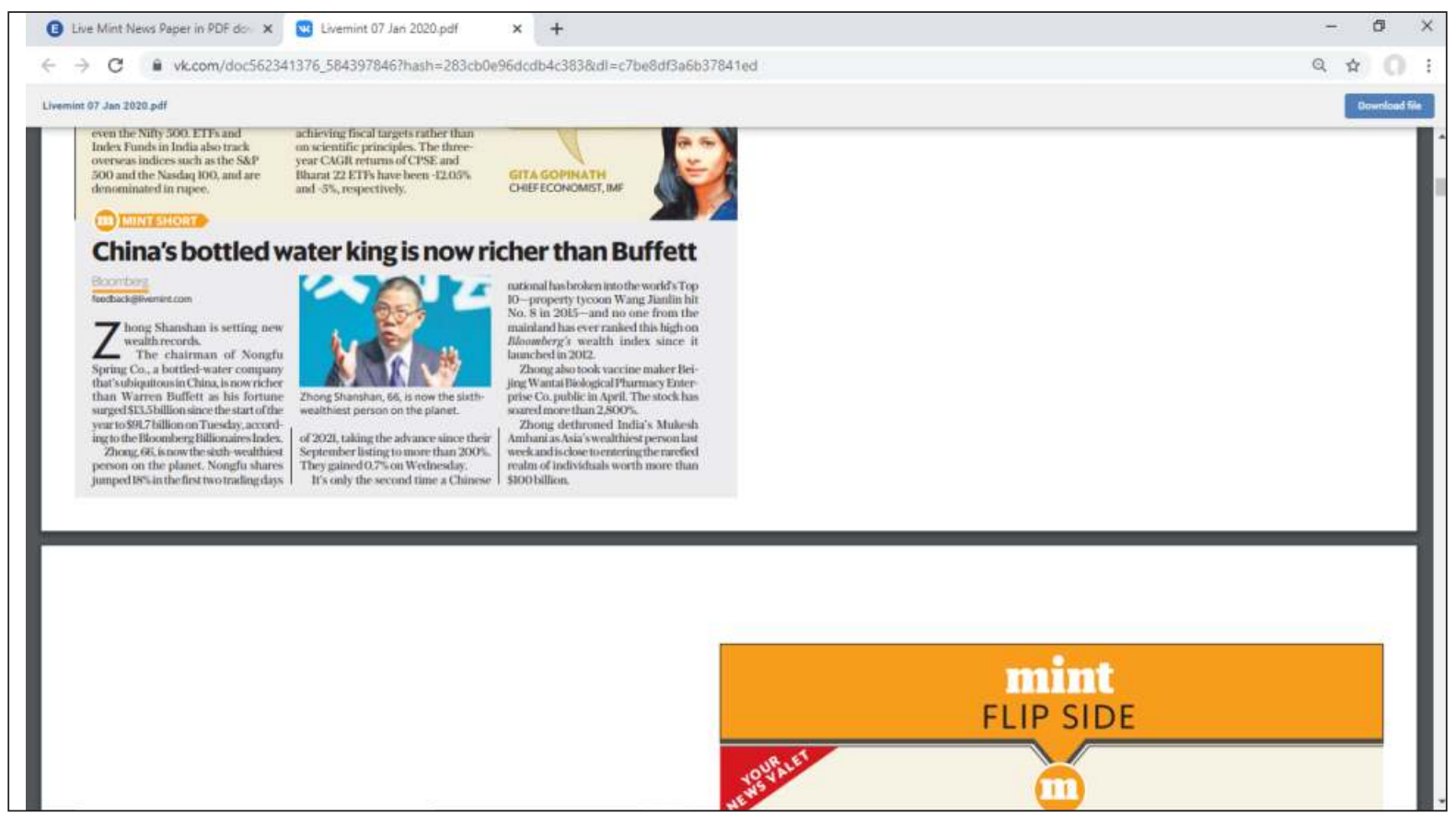

Information regarding mass vaccination for protection against Covid 19 has been reported variedly by different newspapers.

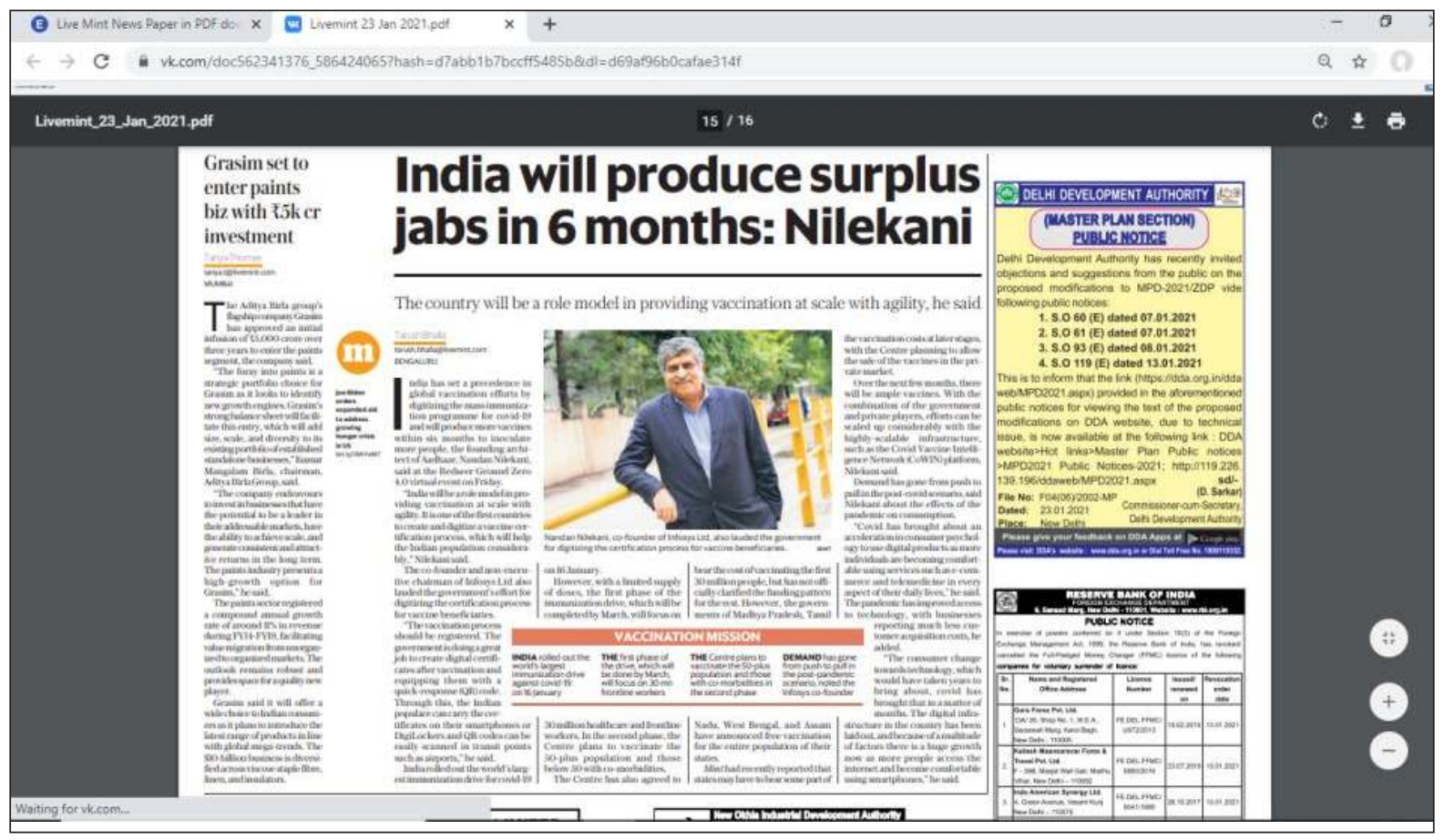



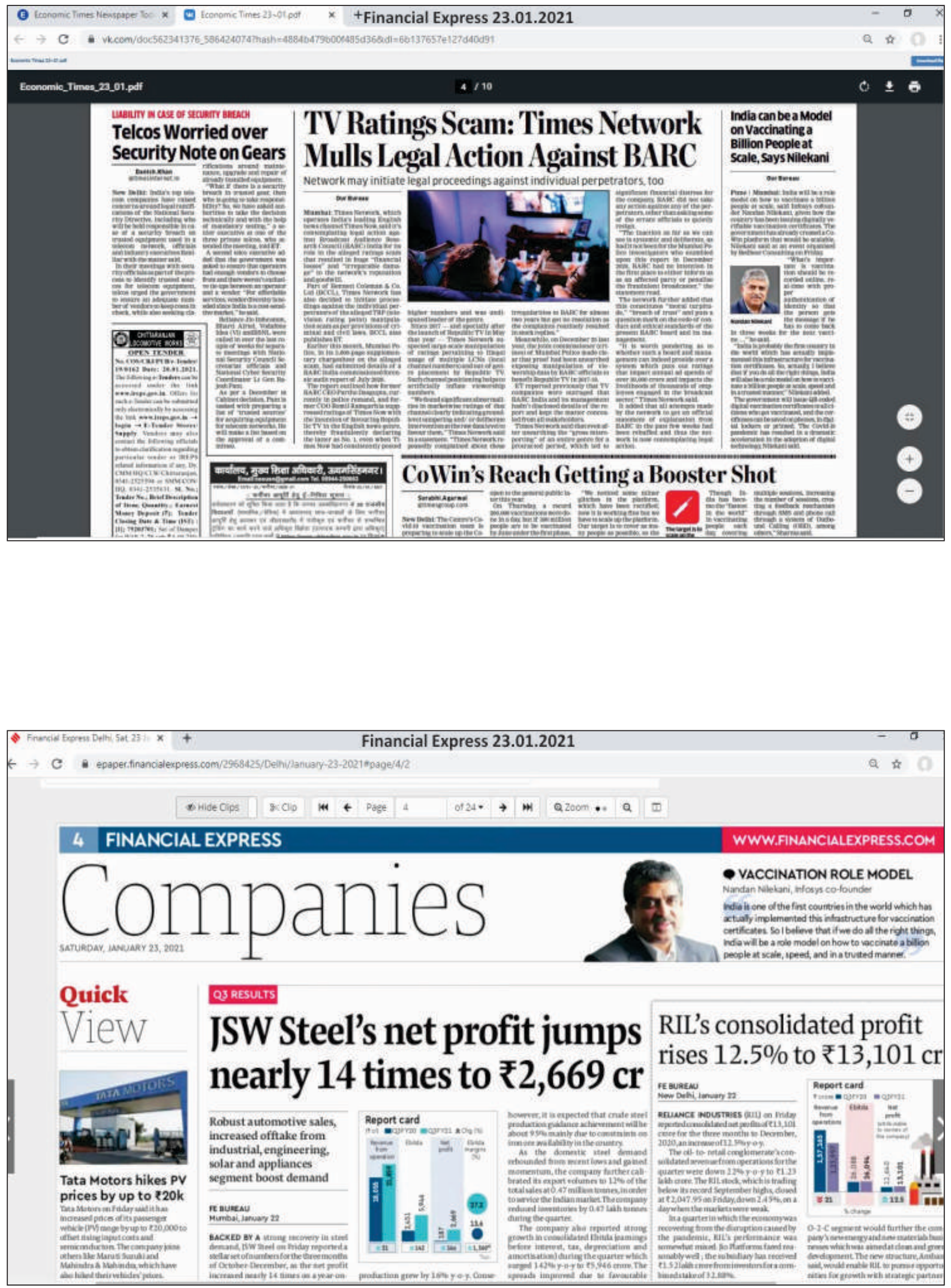


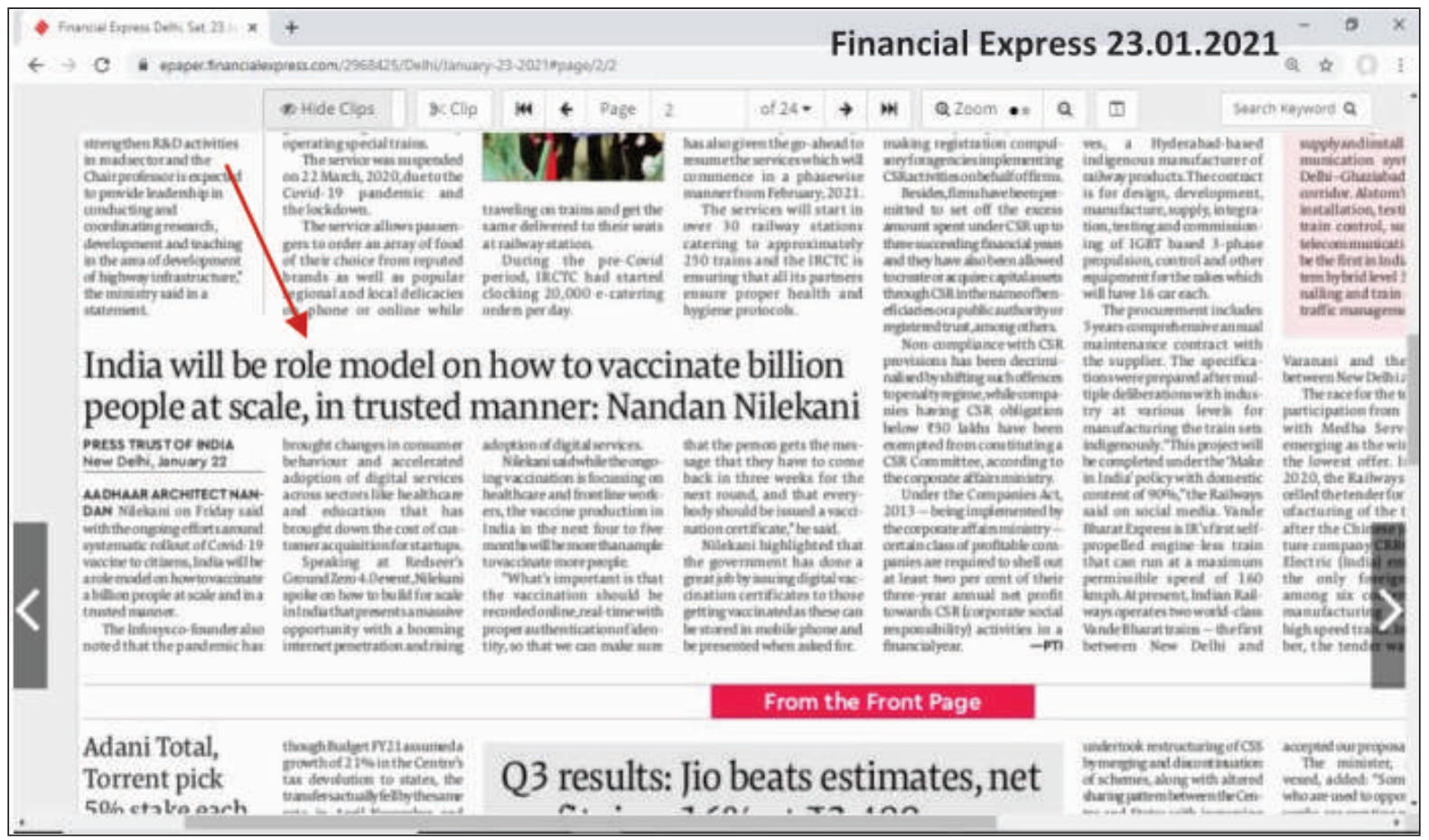

Editorial on E-waste, given below, expands ones understanding of this issue.

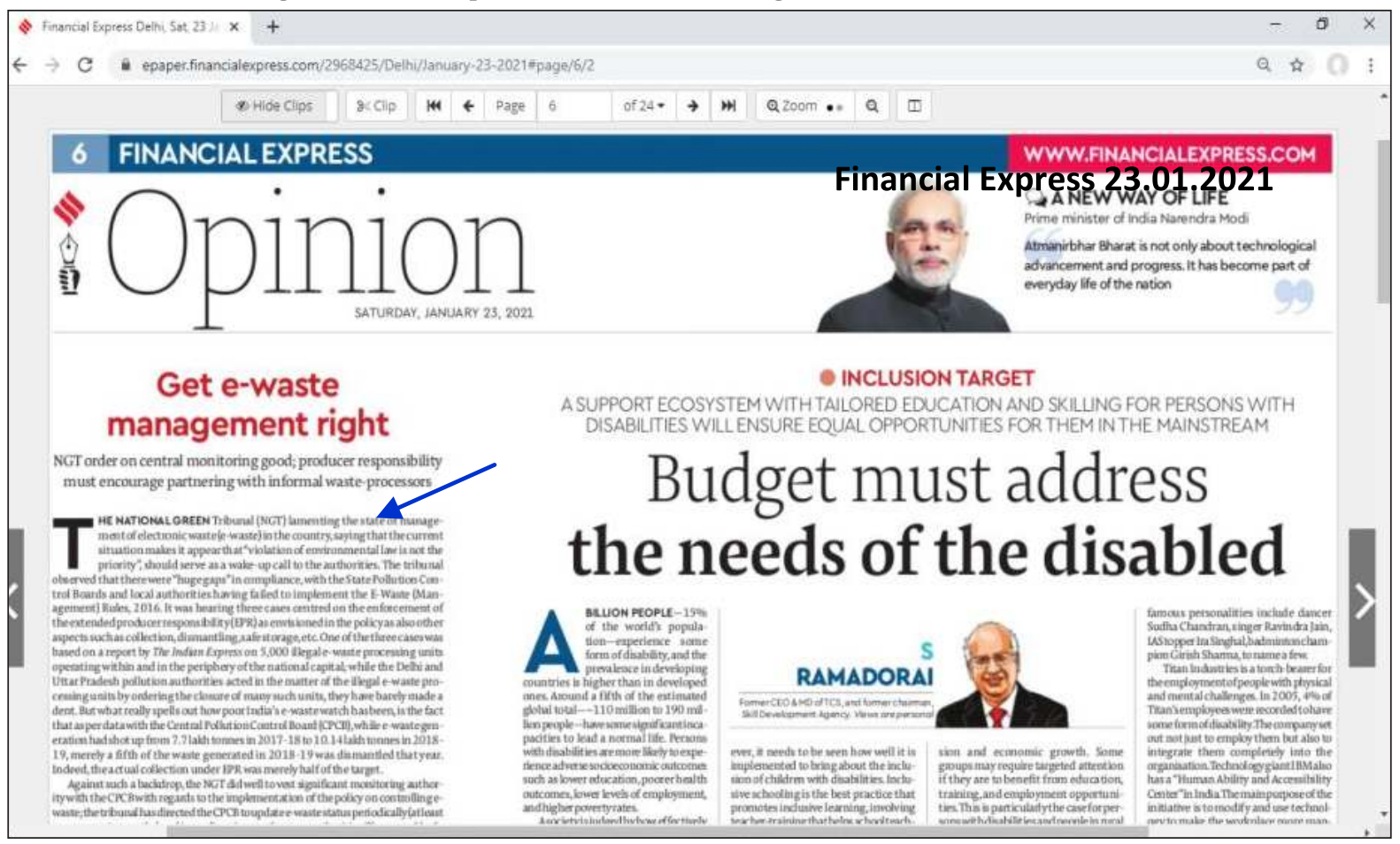


The power of technology's deployment in getting quick and reliable data like count of elephants from space is demonstrated by the following screen shot of Live Mint, 22.01.1021.

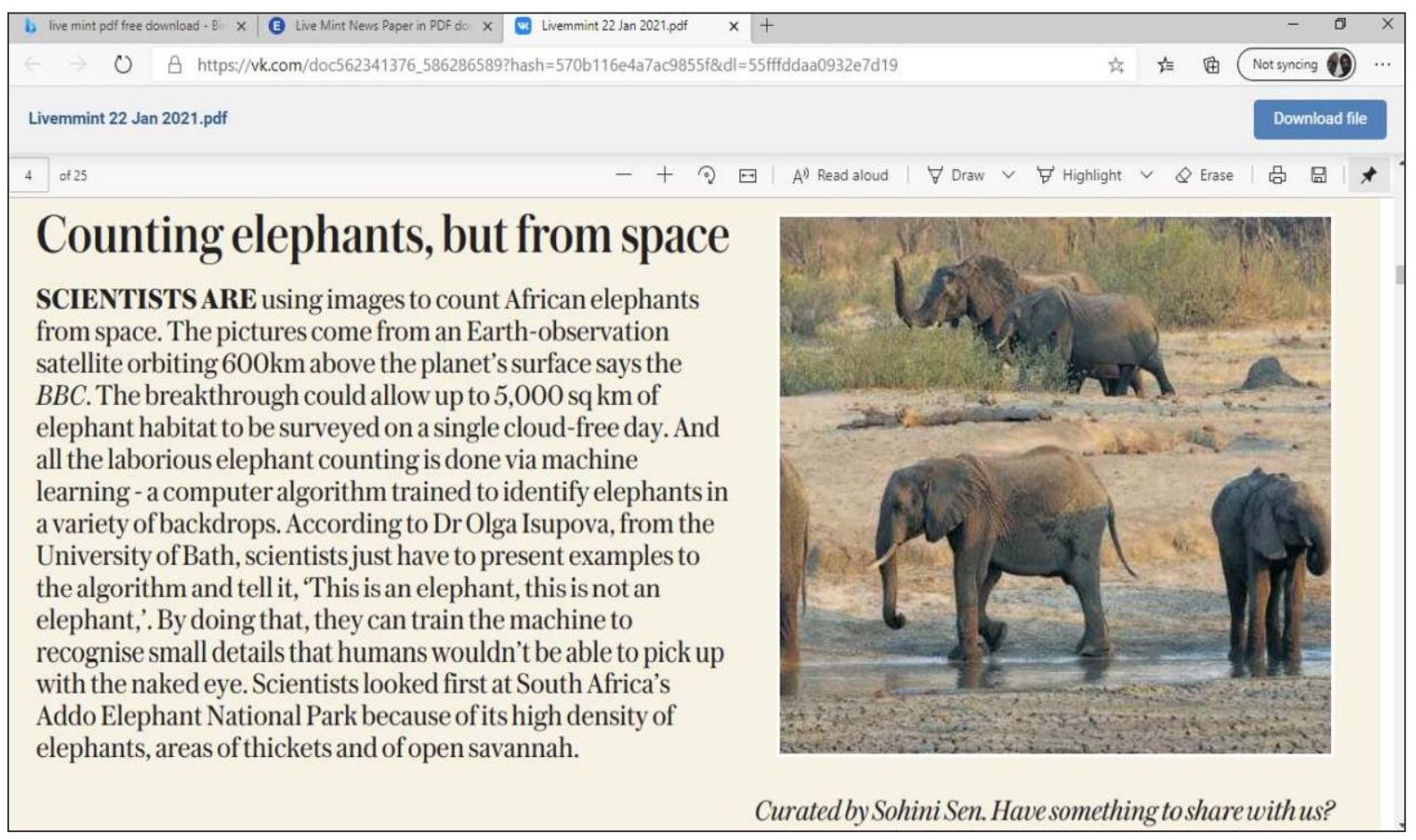

Various dimensional data on climate change as of now can be noted from the following newspaper report.

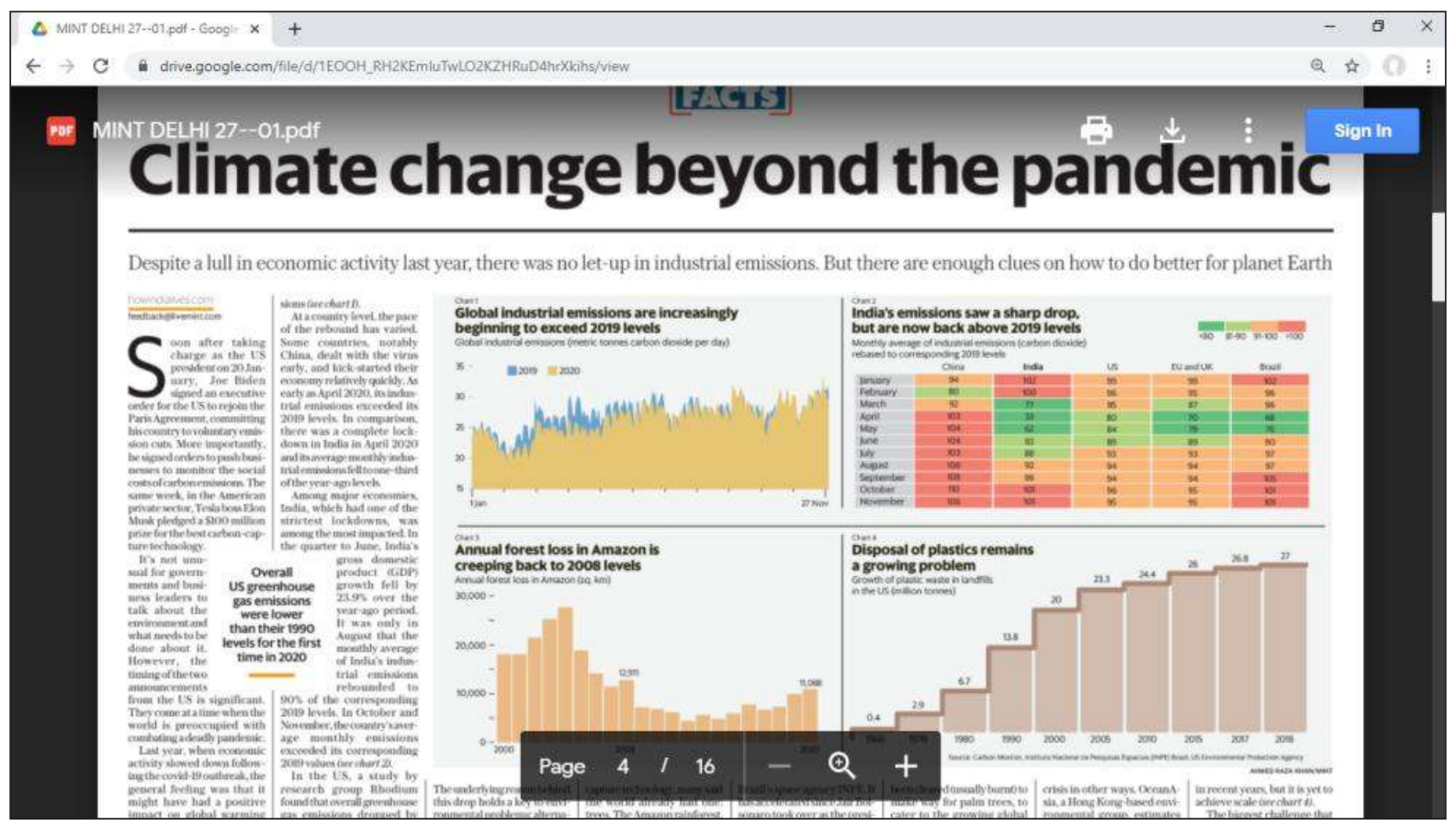


This account has demonstrated how a regular tracking using the simplistic sources of data and information on environment and its different issues can be recorded by an environmentally-conscious person.

\section{REFERENCES}

1. The Gazette of India, Extraordinary Part-II, Section 3, Sub-Section (I)] Government of India, Ministry of Forest and Climate Change $23^{\text {rd }}$ March,2016.

2. IUCN (2020). IUCN SSC Position Statement on the Management of Human-Wildlife Conflict. IUCN Species Survival Commission (SSC) Human-Wildlife Conflict Task Force.

3. https://en.wikipedia.org/wiki/Nuclear_weapon

4. https://www.google.com/search? source=hp\&ei=9uzuX6bvE6Gr3LUPzvuVAs\&q=Bioweapons\&oq=Bioweapons\&gs_lcp= CgZwc3ktYWIQAzIFCAAQyQMyAggAMgII ADICCAAyAggAMgIIADICCAAyAggAMgII

\section{ADICCAA6CAgAEOoCEI8BUI- rBViPqwVgg8IfaAFwAHgAgAH8AygB_AGS AQMyLTGYAQCgAQKgAQGqAQdnd3Mtd2l 6sAEK\&sclient=psy- \\ ab\&ved=0ahUKEwimwoa6t_rtAhWhFbcAHc5 9Bb8Q4dUDCAc\&uact=5}

5. https://www.who.int/health-topics/biologicalweapons\#tab=tab_1

6. https://www.google.com/search? q=Alien + species $+\% 2$ Finvasive + species\&oq=Alien+spe cies $+\% 2$ Finvasive + species $+\& a q s=$ chrome...69i 57.8074j0j15\&sourceid=chrome\&ie=UTF-8

7. Live Mint,16.01.2021

8. Times of India, Delhi Edition, 08.01.2021

9. Live Mint 22.02.2021

10. Financial Express 23.01.2021

11. Live Mint 23.01.2021 